\title{
POLÍTICAS PÚBLICAS E DIREITOS DOS IDOSOS
}

\author{
AMANDA SANTA CRUZ MELO
}




\title{
POLÍTICAS PÚBLICAS E DIREITOS DOS IDOSOS
}

\author{
Amanda Santa Cruz Melo ${ }^{1}$
}

\begin{abstract}
RESUMO
O presente trabalho busca identificar as políticas públicas criadas pelo Poder Público, bem como pela sociedade civil, para assegurar a proteção, promoção e inclusão social dos idosos, no Brasil. Pretende-se resgatar o papel do idoso no seio familiar e comunitário, valorizando o conhecimento adquirido ao longo da existência e respeitando os limites impostos com a chegada da velhice. Contudo, em virtude da inobservância dos direitos humanos, dos preceitos constitucionais e da legislação infraconstitucional, muitas ações conjuntas devem ser realizadas para que este segmento social tenha os seus direitos resguardados, uma vez que o processo de envelhecimento é crescente em todo o mundo e atinge a todos, indistintamente.
\end{abstract}

Palavras-chave:

Idosos. Direitos Humanos. Políticas Públicas. Estatuto do Idoso.

\begin{abstract}
This work looks to identify the public politics created by the Public Power, as well as for the civil society, to secure the protection, promotion and social inclusion of the old ones, in Brazil. The paper of the old one intends to rescue in the familiar and communitarian breast, valuing the knowledge acquired along the existence and respecting the limits imposed with the arrival of the old age. Nevertheless, owing to the inobservance of the human rights, of the constitutional precepts and of the legislation infraconstitucional, many joint actions must be carried out so that this social segment has a right protected, as soon as the process of aging is growing in whole world and reaches to all, without distinction.
\end{abstract}

Key words:

Old. Human Rights. Public Politics. Statute of the Old one.

'Graduada em Direito pela Universidade Federal do Tocantins. Pós-graduanda em Direito e Processo do Trabalho pela UNIDERP/LFG. Servidora concursada no Tribunal de Justiça do Estado do Tocantins.e-mail: amandascm@gmail.com. 


\section{INTRODUÇÃO}

$\mathrm{O}$ aumento da expectativa de vida da população tem sido determinante na evolução social e jurídica do tratamento ao idoso. Um dos maiores desafios da sociedade contemporânea refere-se à luta por questões de desigualdade e exclusão social de determinados segmentos, em um cenário democrático que pressupõe a ampla e irrestrita participação de todos.

É preocupante o crescente envelhecimento populacional, cercado de discriminações e desrespeitos praticados em desfavor das pessoas com idade igual ou superior a 60 anos. Na atualidade, é imprescindível resgatar a visão pretérita do papel do idoso na comunidade, bem como no universo familiar, e descartar o estigma de "ônus social" atribuído indistintamente.

Desta forma, a delimitação do assunto proposto pauta-se no levantamento da legislação correlacionada que verse sobre os direitos específicos da pessoa idosa, enfatizando o Estatuto do Idoso. Ainda, serão abordadas questões a respeito do envelhecimento, em consonância com as políticas públicas, os direitos humanos e os princípios constitucionais que direcionam a atuação do Poder Público no Brasil.

\section{CONSIDERAÇÕES PRELIMINARES SOBRE O IDOSO}

A velhice pode ser entendida como um processo biológico natural, uma etapa da vida, baseada tanto no transcurso do tempo quanto nos efeitos que ele produz no indivíduo. Representa uma fase da existência que certamente apresenta determinadas limitações, da mesma forma que as demais, porém traz compensações insubstituíveis para toda a sociedade, tais como maturidade, experiência e perspectiva de vida pessoal e social.

Avanços da ciência, das políticas públicas e da organização social têm aumentado a expectativa de vida dos indivíduos, ampliando-se para 73,1 anos a idade do homem e 75,6 anos a idade da mulher, mas envelhecer com dignidade ainda é um prêmio a ser conquistado, principalmente pela parcela pobre da população quando submetida às dificuldades habituais (BRASIL, 2007, p. 13).

De acordo com a Pesquisa Nacional por Amostra de 
Domicílios, realizada em 2005 pelo Instituto Brasileiro de Geografia e Estatística (IBGE), o Brasil possui aproximadamente 18.500 .000 pessoas idosas, isto é, $10,5 \%$ da população. Segundo projeções, em 2020 este número chegará a 25 milhões, compondo $11,4 \%$ da população (BRASIL, 2007,p. 13).

Para efeitos legais, considera-se idoso todo indivíduo com idade igual ou superior a 60 anos, ressalvadas as variações apresentadas na determinação da idade quanto a aspectos específicos, como por exemplo, a previsão do benefício assistencial de prestação continuada ao idoso com 65 anos ou mais, que não possua meios para prover sua subsistência, nem de tê-la provida por sua família.

Observadas as leis nacionais, verifica-se que há um paradoxo na idade que define quem é idoso. Enquanto o $\S 2^{\circ}$ do artigo 230 da Constituição vigente garante gratuidade dos transportes coletivos públicos urbanos aos maiores de 65 anos, a Política Nacional do Idoso considera idosa a pessoa com idade a partir de 60 anos. Logo, a Organização Mundial de Saúde, para os países em desenvolvimento, entre os quais o Brasil, possui como referência esta última (ALMEIDA, 2007, p. 30).

\subsection{Papel da entidade familiar}

A família, instituição básica da sociedade, tem uma importância significativa para a formação de todo cidadão. Tratando-se de uma pessoa idosa, essa relevância é aumentada, na medida em que sua integração social ocorrerá através de um bom relacionamento familiar, no qual envolve aceitação da sua condição especial, reconhecimento de seus limites e potencialidades e compreensão dos seus direitos.

Nesse contexto, a presença dos idosos representa a expansão do universo familiar. Toda família teve um passado, vive um presente com suas complexidades e possui regras que provavelmente repetirão nas gerações subseqüentes. É imprescindível que exista na vida dos filhos, netos, bisnetos e avós um espaço em comum para troca de experiências e para o exercício dos sentimentos de respeito e tolerância entre gerações (LEMOS, 2004,p. 177).

O Código Civil de 2002, no subtítulo referente à prestação 
alimentícia, dispõe da seguinte forma:

Art. 1.696. $O$ direito à prestação de alimentos é reciproco entre pais e filhos, e extensivo a todos os ascendentes, recaindo a obrigação nos mais próximos em grau, uns em falta de outros.

Art. 1.697. Na falta dos ascendentes cabe a obrigação aos descendentes, guardada a ordem de sucessão $e$, faltando estes, aos irmãos, assim germanos como unilaterais.

Desta maneira, assim como os pais e avós têm a obrigação de assistir, criar e educar os filhos, os filhos maiores e parentes de grau mais próximo têm o dever de auxiliar e amparar os genitores na velhice, carência ou enfermidade, renovando-se esse ciclo de solidariedade a cada geração.

\section{POLÍTICAS PÚBLICAS: DIREITOS HUMANOS E PRINCÍPIOS CONSTITUCIONAIS}

A Declaração Universal dos Direitos Humanos, proclamada pelas Nações Unidas em 1948, representou a manifestação histórica de reconhecimento dos valores supremos da igualdade, liberdade e fraternidade entre os homens. Dos direitos anunciados na Declaração, dentre outros, o artigo II preconiza a igualdade e repulsa a qualquer tipo de distinção entre os homens quanto à capacidade de gozo de direitos e de liberdades, haja vista que declara essa aptidão à pessoa idosa, a qual não deverá suportar qualquer discriminação em face da idade.

O século XXI tem fortalecido a temática dos direitos humanos, as demandas que envolvem a bioética, os portadores de necessidades especiais e, com grande relevância, os direitos dos idosos. A criação do Estatuto do Idoso (Lei ${ }^{\circ} 10.741 / 03$ ), assim como o da Criança e do Adolescente (Lei $\left.{ }^{\circ} 8.069 / 90\right)$ e das Pessoas com Deficiência (Decreto $\mathrm{n}^{\circ} 3.298 / 99$ ), simbolizam o reconhecimento sócio-político do necessário desenvolvimento de ações de proteção, promoção e inclusão social destes segmentos excluídos de alguma forma.

As políticas públicas tornaram-se uma categoria de real interesse para o direito há aproximadamente vinte anos, com a 
constituição do Estado Democrático de Direito, o qual passou a ter um viés mais comissivo e construtivo. Assim, a atuação estatal baseou-se nas políticas sociais de saủde, seguridade social e outras, centrada principalmente nas funções de coordenação e fiscalização dos agentes públicos e privados (SANTOS, 2006, p. 75).

As citadas políticas públicas são definidas como "metas coletivas conscientes que direcionam a atividade do Estado, objetivando o interesse público", sendo que seguem um processo de no mínimo quatro fases, iniciando-se com a identificação do problema a ser combatido, passando para a formulação e autorização da política, com a aprovação de leis, seguindo na sua implementação para, ao final, chegar à esperada concretização (GARCIA, 1996, p. 66 apud SANTOS, 2006, p. 79).

O Estado enfrenta desafios significativos para implementar políticas públicas voltadas ao idoso, quais sejam: existência de mitos e preconceitos arraigados na cultura da sociedade relativos à velhice e ao processo de envelhecer; ausência ou baixa participação de idosos nas decisões e formulações de políticas sociais; insuficiência de recursos financeiros por parte dos governos federal, estaduais e municipais para a rede de proteção social nas áreas de assistência e saúde; dificuldade de articulação intra e intergovernamental para operacionalização dos programas; carência de conteúdo sobre o envelhecimento nos currículos do ensino fundamental, médio e superior, bem como na qualificação profissional; abuso, violência e maus tratos infligidos aos idosos nos espaços públicos, institucionais e familiares e, por fim, fragilidade da rede pública e privada de promoção, proteção e defesa dos direitos dos idosos (BRASIL, 2007, p. 13-15).

A promoção de amplas e contínuas campanhas educativas sobre violência contra a pessoa idosa, seja na forma física, psicológica e financeira, deve ser prioridade nas políticas públicas. No Brasil, os abusos e maus tratos, em sua maioria, são cometidos pelas famílias, indo desde os castigos em cárcere privado, abandono material, apropriação indébita de bens e objetos, tomada de suas residências, coações, ameaças e mortes. Referentes às instituições públicas e privadas de proteção e da sociedade em geral, os idosos se queixam de maus tratos, desrespeito e negligências (MINAYO, 2005, p. 3033). 
O texto constitucional, no artigo $226, \S 8^{\circ}$, prevê que "o Estado assegurará a assistência à família na pessoa de cada um dos que a integram, criando mecanismos para coibir a violência no âmbito de suas relações". É oportuno asseverar que, em conformidade com o artigo $4^{\circ}, \S 1^{\circ}$, da Lei $10.741 / 03$, "é dever de todos prevenir a ameaça ou violação dos direitos do idoso". Isso quer dizer que incumbe a todos os cidadãos a vigilância para obstruir a prática de intimidações e violências contra os idosos, devendo no mínimo comunicar a ocorrência às autoridades policiais para que tomem as providências cabíveis.

Diante disso, para garantir os direitos humanos e construir as políticas públicas, há de se seguir os princípios constitucionais que, de uma forma geral, possuem superioridade em relação às normas jurídicas, pois servem como fundamento para sua interpretação, bem como determinam o equilíbrio de um sistema jurídico.

\subsection{Dignidade da Pessoa Humana}

A dignidade da pessoa humana é um atributo inerente aos seres humanos, diferente de ser um direito outorgado pelo ordenamento jurídico. A sua previsão no texto constitucional simboliza o dever de proteção pelo Estado, bem como almeja garantir o respeito recíproco entre os indivíduos.

A proteção da dignidade humana deve ser entendida como o alicerce de todos os direitos fundamentais, variando conforme o grau de derivação, ou seja, enquanto a vida, a liberdade e a igualdade resultam diretamente da referida dignidade humana, outros direitos são apenas derivações indiretas ou de segundo grau (CAMARGO, 2006, p. 48).

O reconhecimento da dignidade da pessoa humana como um dos fundamentos da República impõe aos poderes públicos o dever não só de observar e proteger esse valor, mas também de promover os meios necessários ao alcance das condições mínimas indispensáveis a uma vida digna e ao pleno desenvolvimento da personalidade (NOVELINO, 2008, p. 207).

Com relação aos idosos, o respeito à dignidade significa a não realização de atividades que comprometam suas limitações físicas e psíquicas, enquanto a proteção resulta de ações positivas que tentam 
evitar qualquer tipo de violação e abuso por parte de terceiros e, por fim, a promoção visa propiciar condições necessárias que assegurem uma vida digna e adequada.

Assim sendo, para que a dignidade de cada idoso seja garantida é necessário asseverar o mínimo existencial, qual seja, saúde e moradia. O Estado deve fornecer remédios e proporcionar tratamentos indispensáveis à sobrevivência destes, com atendimento preferencial no Sistema Único de Saúde (SUS), assim como deve prestar assistência habitacional quando o indivíduo da terceira idade não possui recursos financeiros próprios ou da família, nem moradia apropriada no seio familiar.

\subsection{Liberdade}

O exercício da liberdade proporciona aos seres humanos a prática da escolha e definição dos caminhos a serem seguidos na vida. No título referente aos direitos fundamentais, o Estatuto do Idoso prevê o direito à liberdade, ao respeito e à dignidade no mesmo capítulo.
Art. 10. É obrigação do Estado e da sociedade, assegurar à pessoa idosa a liberdade, o respeito e a dignidade, como pessoa humana e sujeito de direitos civis, politicos, individuais e sociais, garantidos na Constituição e nas leis.
$\S 100$ direito à liberdade compreende, entre outros, os seguintes aspectos:
7 - faculdade de $i$, vir e estar nos logradouros públicos e espaços comunitários, ressalvadas as restrições legais;
II-opinião e expressão;
III-crença e culto religioso;
$I V$ - prática de esportes e de diversões;
$V$ - participação na vida familiar e comunitária;
VI-participação na vida politica, na forma da lei;
VII-faculdade de buscar refúgio, auxilio e orientação

Desse modo, a liberdade do idoso deve ser a mais ampla possível, ressalvadas as restrições legais, destacando-se o direito de expor suas opiniões e se expressar livremente, exteriorizando o seu juízo de valor sobre assuntos de qualquer natureza. Acerca de sua convicção religiosa, é livre a opção de escolha e a participação de 
cultos distintos, bem como deve ser preservada a sua autonomia financeira adquirida ao longo da sua existência.

Cabe ao Estado criar um sistema de limitação às liberdades individuais, para evitar interferência no exercício dos direitos de outrem, garantindo a máxima expansão física e intelectual dos idosos, prioridades da liberdade.

\subsection{Igualdade}

O princípio da igualdade pode ser conceituado como "inadmissibilidade de diferenciações de tratamento arbitrárias, exteriorizadas sob a forma de discriminações (situações de desvantagem) ou privilégios (situações de vantagem)" (CAMARGO, 2006, p. 144).

Com efeito, o princípio divide-se em igualdade formal, também conhecida como igualdade perante a lei, na qual assegura a criação e aplicação igualitária das regras jurídicas e igualdade material, na qual considera que cada indivíduo vive dentro de características e circunstâncias próprias.

Todavia, a prática demonstrou que esta igualdade meramente formal não era capaz de coibir as injustiças e discriminações, colocando os indivíduos em condições desiguais. Assim, surgiu a necessidade da materialização do conceito de igualdade, fazendo com que as situações fossem analisadas individualmente para se identificar qual tratamento aplicar ao caso concreto.

Além da noção geral do princípio da igualdade material, consistente no tratamento igual a situações iguais e tratamento desigual a situações desiguais, a Constituição Federal de 1988, no artigo $5^{\circ}$, caput, veda distinções de qualquer natureza. Sobre as discriminações, o requisito da idade, no que tange às relações de emprego, tem sido um obstáculo para os idosos, seja na recusa do trabalho ou no pagamento de salários inferiores àqueles recebidos pelos trabalhadores mais jovens.

Logo, as ações afirmativas consistem em políticas públicas ou programas privados desenvolvidos com o intuito de minimizar as desigualdades que decorrem de discriminações ou de hipossuficiência, econômica ou física, através da concessão de alguma vantagem compensatória (NOVELINO, 2008, p. 294). 


\subsection{Justiça}

A prioridade do idoso deixou de ser um simples valor moral para se tornar em um valor protegido pelo ordenamento jurídico brasileiro. Em face das condições naturais e sociais adversas ao idoso, o resultado processual justo somente é possível se vier tempestivamente, isto é, dentro dos limites razoáveis de espera no desenrolar da justiça.

Em termos legais, o artigo 71 e seus parágrafos da Lei $n^{\circ}$ 10.741/03 asseguram a prioridade na tramitação e julgamento de processos, em todos os atos e diligências, quando figurar como parte ou interveniente pessoa com idade igual ou superior a 60 anos, não cessando o direito com sua morte, pois que se estende em favor do cônjuge supérstite, companheiro ou companheira, em união estável, também com a idade supracitada.

Para ter direito à prioridade na justiça, o idoso não precisa litigar sozinho na demanda, isto é, mesmo em litisconsórcio necessário ou facultativo com outras partes tendo idade inferior a 60 anos, a pessoa idosa terá a preferência respeitada, competindo a(o) juiz(a) examinar eventuais abusos.

\section{ASPECTOS HISTÓRICOS DOS DIREITOS DOS IDOSOS NO BRASIL}

A Constituição Federal de 1988 representou o marco inicial para a definição da Política Nacional do Idoso, pois traçou os direitos desse público e delimitou as diretrizes a serem seguidas, impondo à família, à sociedade e ao Estado o dever de amparar os idosos.

Na ocasião, através do artigo $14, \S 1^{\circ}$, II, "b" da Carta Magna, o voto tornou-se facultativo para os idosos com idade superior a 70 anos, tendo como fundamento o sacrifício e as dificuldades enfrentadas no dia das eleições, incluindo a superlotação dos transportes públicos, as péssimas instalações físicas das seções eleitorais e, principalmente, a diminuição da capacidade de locomoção dos idosos.

Em 1994, após a criação da Política Nacional do Idoso, fruto de articulação entre vários órgãos do governo, as instituições de ensino 
superior passaram a se adaptar às determinações legais, nas quais prevêem a existência de cursos de Geriatria e Gerontologia Social nas faculdades de Medicina do país. Vale ressaltar que, segundo o IBGE, a geriatria é uma especialidade da medicina que trata da saúde do idoso, enquanto a gerontologia vem a ser a ciência que estuda o envelhecimento.

Ainda, destaca-se que as autoridades públicas brasileiras intensificaram a mobilização em favor de políticas específicas para os idosos a partir do episódio trágico ocorrido na Clínica Santa Genoveva (casa de saúde privada, custeada por recursos públicos), no Rio de Janeiro, em 1996. Na ocasião, uma centena de idosos faleceu no período de apenas um mês, por falta de higiene e tratamento adequado, alcançando repercussão até mesmo internacional(LEMOS, 2004, p. 117-130).

\subsection{Evolução legislativa}

A Lei Federal $\mathrm{n}^{\circ} 8.842$, de 04 de janeiro de 1994, determinou a Política Nacional do Idoso, bem como criou o Conselho Nacional dos Direitos do Idoso, este último regulamentado pelo Decreto $\mathrm{n}^{\circ}$ 5.109, de 17 de junho de 2004.

Em 08 de novembro de 2000, a Lei Federal $n^{\circ} 10.048$ estabeleceu prioridade no atendimento ao idoso maior de 65 anos, em todos os bancos, órgãos públicos e concessionárias de serviço público. Destaca-se que, com a redação da nova lei - Estatuto do Idoso -, esta idade foi reduzida para 60 anos.

A Lei Federal $n^{\circ} 10.098$, de 19 de dezembro de 2000, elencou critérios para a promoção da acessibilidade das pessoas com mobilidade reduzida, incluindo os idosos.

Já a Lei $\mathrm{n}^{\circ} 10.173$, de 09 de janeiro de 2001, incluiu as alíneas "a", "b" e "c" no artigo 1.211 do Código de Processo Civil, estabelecendo prioridade na tramitação de processos judiciais de idosos, maiores de 65 anos, em qualquer instância ou tribunal.

Em maio de 2002, o governo federal instituiu o Programa Nacional de Direitos Humanos, que considera como público-alvo todos os grupos populacionais específicos passíveis de discriminações, entre os quais, o de pessoas idosas.

Finalmente, após sete anos de tramitação no Congresso 
Nacional, ocorreu a aprovação do Estatuto do Idoso, isto é, da Lei 10.741 , em $1^{\circ}$ de outubro de 2003, representando um marco legal para a consciência idosa do país. Houve a redefinição do lugar das pessoas com idade igual ou superior a 60 anos, chamando-as para exigir proteção aos seus direitos e se reintegrarem na vida comunitária.

Insta salientar que entrou em vigor o Decreto Federal $n^{\circ} 5.934$, de 18 de outubro de 2006, estabelecendo os critérios a serem adotados na aplicação do disposto no artigo 40 da Lei 10.741/03, relativo ao transporte coletivo interestadual rodoviário, ferroviário e aquaviário.

Em 19 de novembro de 2007, a Lei Federal n ${ }^{\circ} 11.551$ instituiu o Programa Disque Idoso, com a finalidade de atendimento a denúncias de maus tratos e violência contra os idosos com idade a partir de 60 anos.

\section{ESTATUTO DO IDOSO}

Sobre os beneficiários do Estatuto do Idoso, em regra as pessoas com idade igual ou superior a 60 anos têm direito à educação, saúde, cultura, esporte, lazer, bem como ao exercício de atividade profissional.

O consumidor idoso tem direito a atendimento prioritário e específico, com condições adequadas para que exerça sua autonomia na hora de consultar, comprar um produto ou contratar um determinado serviço. Tanto os órgãos públicos quanto os privados, prestadores de serviços, devem oferecer atendimento preferencial individualizado ao idoso, a exemplo dos caixas específicos, para tornar mais célere e confortável o atendimento (artigo $3^{\circ}, \S$ único, inciso I).

Referente à cultura, esporte, lazer, diversões, espetáculos e serviços que respeitem a condição de idade do idoso, o Estatuto prevê o direito a descontos de pelo menos $50 \%$ no valor do ingresso para eventos artísticos, culturais e de lazer. Vale dizer que, nesses locais, o acesso preferencial deve ser observado, ou seja, é suficiente a apresentação da carteira de identidade ou documento equivalente (artigo 23).

Nesse contexto, a pessoa idosa tem direito a atendimento 
preferencial na Defensoria Pública da União, dos Estados e do Distrito Federal no que se refere aos serviços de assistência judiciária que estejam relacionadas à sua condição de idoso (art. 71, $\left.\S 3^{\circ}\right)$.

Nos programas habitacionais públicos, o Estatuto do Idoso estabelece que as pessoas com 60 anos ou mais têm prioridade na aquisição da casa própria, uma vez que $3 \%$ das unidades residenciais devem estar reservadas para atendê-los. Também deve haver critérios de financiamento adequados aos rendimentos da aposentadoria ou pensão do idoso, caso este queira adquirir tais imóveis (art. 38, I e IV). Ainda, exige-se que nestes projetos habitacionais haja implantação de equipamentos urbanos comunitários voltados aos idosos, assim como uma estrutura que elimine barreiras arquitetônicas e urbanísticas, garantindo a acessibilidade (art. 38, II e III).

Contudo, apesar do Estatuto do Idoso ser uma legislação recente, o esforço despendido pelo conjunto de voluntários, aqui incluídas as instituições públicas e privadas, deve buscar a consolidação dos propósitos focados na Constituição Federal e nos direitos humanos.

\subsection{Saúde e Assistência Social}

Historicamente, uma das melhorias na saúde ocorreu a partir do ato de lavar as mãos. Um gesto simples que, em meados do século XIX, possibilitou a longevidade da população (ZABAGLIA, 2004, p. 187).

Desde 1999 a Campanha Nacional de Vacinação do Idoso é realizada no Brasil, em parceria com as Secretarias Municipais e Estaduais de Saúde. O principal objetivo da vacina é evitar a gripe, diminuir os riscos de complicações, principalmente de pneumonia, que provoca internação hospitalar, e reduzir a morbi-mortalidade.

A Política Nacional de Saúde do Idoso tem como propósito basilar a promoção do envelhecimento ativo e saudável, a manutenção e melhoria da capacidade funcional, a prevenção de doenças, a recuperação da saúde dos que adoecem e a reabilitação daqueles que venham a ter sua capacidade restringida. Ainda, é assegurado ao idoso o direito de optar pelo tratamento médico que 
considerar mais adequado para si, desde que suas faculdades mentais estejam preservadas. No que se refere aos planos de saúde privados, é vedada a discriminação do idoso com a cobrança de valores diferenciados em razão da idade (artigo $15, \S 3^{\circ}$ do Estatuto do Idoso).

São responsabilidades do poder público, na área da saúde, garantir assistência integral ao idoso, entendida como o conjunto articulado e contínuo de ações e serviços preventivos e curativos; permitir o amplo acesso a hospitais e clínicas; fornecer gratuitamente medicamentos, especialmente os de uso contínuo, como próteses, órteses e demais recursos relativos ao tratamento e reabilitação; desenvolver política de prevenção para que a população envelheça mantendo um bom estado de saúde; criar serviços de atendimento domiciliar; produzir e distribuir material educativo sobre a saúde, alimentação adequada e sexualidade do idoso e, por fim, estimular o autocuidado.

A distinção entre o sistema previdenciário e a assistência social é simples, uma vez que o primeiro requer contribuição antecipada para que os benefícios sejam disponibilizados, enquanto que a segunda não exige contribuição para gozo dos benefícios da assistência, apenas sendo necessária a comprovação incontestável de hipossuficiência por parte do beneficiário.

Por conseguinte, conforme elucida o artigo 34 do Estatuto do Idoso, o acesso dos idosos ao benefício da prestação continuada é possível com o cumprimento do requisito da idade mínima de 65 anos de idade. Também deve ser observada a renda mensal familiar per capita inferior a um quarto do salário mínimo $\left(\S 3^{\circ}\right.$ do artigo 20 da Lei Orgânica da Assistência Social - Loas), questão esta bastante questionada pelos doutrinadores.

\subsection{Programas habitacionais}

Os artigos 37 e 38 do Estatuto do Idoso versam sobre o direito de habitação para os idosos. Tais regras dão ensejo a que o idoso, preferencialmente, resida com sua família, no entanto, caso esta não tenha condições de mantê-lo em casa ou quando ele assim desejar, poderá morar ou se abrigar em instituições públicas, devendo ser prestada a devida assistência em todos os sentidos. 
Algumas recomendações foram editadas para instituições públicas e privadas que cuidam de pessoas idosas, através do Manual de Funcionamento da Sociedade Brasileira de Geriatria e Gerontologia, a saber: o terreno deve ser preferencialmente plano e, se inclinado, precisa ter escadas e rampas para eliminar os desníveis; a área de circulação de idosos precisa ser isolada do local de circulação de veículos; os acessos, internos e externos, devem ocorrer por corredores planos, escadas ou rampas sem qualquer obstáculo; os pisos externos, inclusive rampas e escadas, devem ser de material de fácil limpeza, antiderrapante, uniformes e contínuos; rampas e escadas devem ter corrimãos que destaquem da parede, seja pela cor ou material utilizado; as áreas internas devem ter boa iluminação artificial e natural, além de ventilação natural; todos os cômodos precisam ter luz de vigília, campainha para emergência e sistema de segurança para prevenção de incêndio; em construções novas, as janelas devem ter comando de abertura em forma de alavanca; os dormitórios devem ter luz de vigília e campainha de alarme nas cabeceiras; os banheiros precisam ter campainha de alarme, luz de vigília próxima à porta externa; deve haver, no mínimo, um vaso sanitário para cada cinco usuários e um chuveiro com água quente para cada dez leitos; cortinas plásticas e portas de acrílico ou vidro devem ser evitadas (SAMPAIO, 2004, p. 41).

\subsection{Transporte eAcessibilidade}

De acordo com a Lei Federal $n^{\circ} 10.098 / 00$, devem ser observados critérios básicos para a promoção da acessibilidade das pessoas com mobilidade reduzida, mediante a supressão de barreiras e obstáculos nas vias e espaços públicos, no mobiliário urbano, na construção e reforma de edifícios.

Esta melhoria no acesso aos meios de transporte, prédios públicos e privados, ruas, calçadas e praças, através de rampas, portas mais largas, barras em corredores e banheiros e toda adaptação necessária, buscam facilitar a mobilidade do idoso, garantindo uma circulação segura e com mais conforto.

Referente à reserva de vagas nos estacionamentos públicos e privados, é assegurada no mínimo 5\%, variando conforme a lei local (art. 41 do Estatuto do Idoso). 
Conforme elucida o Estatuto do Idoso, são reservados $10 \%$ dos assentos, identificados com placas ou adesivos que alertem quanto à preferência para idosos (art. $39, \S 2^{\circ}$ ). A constitucionalidade deste artigo foi questionada por meio da Ação Direta de Inconstitucionalidade $\mathrm{n}^{\circ} 3.768$-DF; porém, o Supremo Tribunal Federal julgou improcedente a ação, com fundamento de que o dispositivo legal faz alusão ao disposto no $\S 2^{\circ}$ do artigo 230 da Constituição do Brasil, qual seja: "aos maiores de sessenta e cinco anos é garantida a gratuidade dos transportes coletivos urbanos".

No sistema de transporte coletivo interestadual, ressalvados os critérios definidos pelos órgãos competentes, ficam resguardadas no mínimo duas vagas gratuitas por veículo para idosos com renda igual ou inferior a dois salários mínimos e desconto de $50 \%$ do valor da passagem para os idosos de mesma renda que excedam essa reserva (art. 40, incisos I e II da Lei 10.741/03).

É importante salientar que devem ser observados os prazos para solicitação do bilhete de passagem, bem como antecedência mínima na hora do embarque, conforme previsto no mencionado Decreto $\mathrm{n}^{\circ}$ 5.934/06. Entretanto, caso a empresa obste o deferimento da passagem, o idoso deve procurar imediatamente a delegacia especializada, a Defensoria Pública ou o Ministério Público local, para serem tomadas as devidas providências.

\subsection{Comunicação e Universidade}

Os meios de comunicação devem reservar horários voltados para o público idoso, com finalidade educativa, informativa e cultural sobre o processo de envelhecimento e seus aspectos biopsicossociais, conforme disposto no artigo 24 do Estatuto do Idoso. Uma iniciativa da televisão brasileira é a Campanha da Fraternidade, organizada desde 1964 pela Conferência Nacional dos Bispos do Brasil.

À medida que aumenta a responsabilidade do Estado, em paralelo cresce a exigência para aos particulares, detentores de concessões de meios de comunicação social (emissoras de televisão, rádio e jornais), que devem priorizar o incentivo e a valorização das pessoas idosas.

Para incentivar a educação voltada à terceira idade, $\mathrm{o}$ artigo 25 
da Lei 10.741/03 determina que o Poder Público "apoiará a criação de universidade aberta para as pessoas idosas e incentivará a publicação de livros e periódicos, de conteúdo e padrão editorial adequados ao idoso, que facilitem a leitura, considerada a natural redução da capacidade visual".

As Universidades da Terceira Idade têm representado uma experiência significativa, visto que proporcionam aos idosos a oportunidade de se manterem atualizados, além de realizarem contatos com pessoas motivadas a prosseguir na busca de novos conhecimentos.

Nesse sentido, a Universidade Estadual do Rio de Janeiro (UERJ) foi pioneira, antecipando até mesmo ao legislador infraconstitucional, isto é, em 1993 foi constituída a Universidade Aberta da Terceira Idade, através da iniciativa do professor Piquet Carneiro. A partir de então, o exemplo da UERJ foi seguido por diversas instituições brasileiras (LEMOS, 2004, p. 41).

\subsection{Ministério Público}

O Estatuto do Idoso atribui ao Ministério Público, à Vigilância Sanitária e aos Conselhos dos Idosos, a função de fiscalizar os estabelecimentos que atendem pessoas idosas, imputando penalidades administrativas àqueles que descumprirem as determinações legais, conforme a natureza e a gravidade da infração praticada, os danos causados e as circunstâncias, agravantes e atenuantes. As sanções implicam no pagamento de multas, devendo ser aplicadas às entidades assistenciais e aos profissionais da saúde que infringirem a legislação.

A Constituição Federal vigente ampliou a atuação do Ministério Público, deixando de ser um órgão eminentemente acusador para também defender os direitos individuais e sociais, nas mais diversas áreas da atividade humana, incluindo os idosos, nos termos do caput do artigo 127.

A Lei Orgânica Nacional do Ministério Público, $\mathrm{n}^{\circ} 8.625$, de 12 de fevereiro de 1993, no inciso IV do artigo 25 , traz outra importante função, a saber:

Art. 25. Além das funções previstas nas Constituições Federal e Estadual, na Lei Orgânica e em outras leis, 
incumbe, ainda, ao Ministério Público:

[...]

IV-promover inquérito civil e a ação civil pública, na forma da lei:

a) para a proteção, prevenção e reparação dos danos causados ao meio ambiente, ao consumidor, aos bens e direitos de valor artístico, estético, histórico, turístico e paisagístico, e a outros interesses difusos, coletivos $e$ individuais indisponiveis e homogêneos.

Com redação semelhante, o artigo 74 do Estatuto do Idoso dispõe sobre a instauração de inquérito civil e de ação civil pública. Logo, é dever de cada Ministério Público Estadual fiscalizar as atividades do Estado e, se necessário, acionar o Poder Judiciário para exigir o respeito aos direitos dos idosos.

\section{CONCLUSÃO}

O envelhecimento faz parte da própria natureza humana, porém a busca pela eterna juventude tem sido prioridade para muitos indivíduos, em razão do aumento progressivo da expectativa de vida da população. Se antes era apenas um problema individualizado, atualmente também representa uma preocupação da sociedade e do Poder Público.

O dever do Estado de tutelar os direitos dos idosos está inserido em diversos dispositivos constitucionais, incluindo a previsão da dignidade da pessoa humana como princípio fundamental, além da igualdade por meio do tratamento diferenciado, sem preconceito de idade e, por fim, as determinações do artigo 230, que asseguram o direito à vida, ao amparo e a defesa do bem-estar.

Apesar da aludida proteção constitucional, vários abusos são constatados diariamente, indo desde o desrespeito nos hospitais, descaso nos transportes públicos, maus tratos praticados pelos familiares e demora no atendimento das repartições públicas, entre outros problemas ainda não solucionados.

Principalmente em virtude do distanciamento entre as gerações, foi necessária a intervenção do Estado nas relações em que o idoso está inserido. Além dos programas promovidos pelo governo, a importância dos serviços prestados gratuitamente pela Defensoria Pública, aliados à atuação dos Conselhos e do Ministério Público na 
promoção da defesa dos direitos do idoso, deve ser observada e senão cobrada constantemente pelos interessados.

Todavia, se os preceitos constitucionais e a Declaração Universal dos Direitos Humanos fossem respeitados, não seria essencial a criação de leis específicas para regulamentar o direito de diferentes segmentos, a exemplo dos estatutos. A criação da Lei $\mathrm{n}^{\circ}$ $10.741 / 03$, considerada como o Estatuto do Idoso, representou um instrumento fundamental de propulsão para a execução das políticas públicas, que tanto visam proteger o idoso quanto integrá-lo ao meio social em que vivem. Tal iniciativa não significou alcance máximo, ou seja, a divulgação e conscientização dos direitos do idoso, inclusive para os próprios beneficiados, tem sido o passo longo ainda em sua fase inicial.

Não obstante as conquistas obtidas e os avanços verificados na legislação brasileira para garantir a defesa dos direitos da pessoa idosa, existem barreiras e desafios a serem superados pelo país.

Em suma, é necessário sensibilizar a sociedade e as entidades institucionais para estabelecer ações conjuntas que visem integrar as gerações e valorizar o idoso como ser humano que é, possibilitando assim o protagonismo da pessoa idosa e o envelhecimento digno e , saudável.

\section{REFERÊNCIAS}

ALMEIDA, Vera Lúcia V.; GONÇALVES, M. P.; LIMA, T. G. Direitos Humanos e pessoa idosa. Brasília, DF: Secretaria Especial dos Direitos Humanos, 2007.

ANGHER, Anne Joyce (Org.). Vade Mecum Acadêmico de Direito. 5. ed. São Paulo: Rideel, 2007.

BRASIL. Presidência da República. Secretaria Especial dos Direitos Humanos, Subsecretaria de Promoção e Defesa dos Direitos Humanos. Controle democrático com garantia de Direitos da Pessoa Idosa. Brasília, DF: 2007.

. Subsecretaria de Promoção e Defesa dos Direitos Humanos. Princípios das Nações Unidas em favor das pessoas idosas. Brasília, DF: [1991?]. 
CAMARGO, Marcelo Novelino (Org.). Leituras complementares de Direito Constitucional. Salvador: Juspodivm, 2006.

HENRIQUE, Antonio; MEDEIROS, João Bosco. Monografia no Curso de Direito: como elaborar o trabalho de conclusão de curso (TCC). 5. ed. São Paulo: Atlas, 2006.

IBGE. Política do Idoso no Brasil. Disponível em:

$<$ http://www.ibge.gov.br/ibgeteen/datas/idoso/politica_do_idoso_ o brasil.html>

Acesso em: 29 abr. 2010.

LEMOS, Maria Teresa Toríbio Brittes; ZABAGLIA, Rosângela Alcântara (Orgs.). A arte de envelhecer: saúde, trabalho, afetividade e Estatuto do Idoso. Rio de Janeiro: Idéias \& Letras, 2004.

MINAYO, Maria Cecília de Souza. Violência contra idosos: o avesso do respeito à experiência e à sabedoria. 2. ed. Brasília, DF: Presidência da República. Secretaria Especial dos Direitos Humanos, Secretaria de Promoção e Defesa dos Direitos Humanos, 2005.

NOVELINO, Marcelo. Direito Constitucional. 2. ed. São Paulo: Método, 2008.

ONU. Declaração Universal dos Direitos Humanos. Disponível em:

$<$ http://www.mj.gov.br/sedh/ct/legis_intern/ddh_bib_inter_univers al.htm> Acesso em: 30 abr. 2010.

Plano Nacional de Implementação das Deliberações. In: CONFERENCIA NACIONAL DOS DIREITOS DA PESSOA IDOSA, I., 2007, Brasília, DF: Anais... Brasília, DF: Presidência da República. Secretaria Especial dos Direitos Humanos, Conselho Nacional dos Direitos do Idoso.

SAMPAIO, Luiz Augusto Paranhos. Estatuto do idoso: 
comentado. Goiânia: AB, 2004.

SANTOS, Marília Lourido dos. Interpretação constitucional no controle judicial das políticas públicas. Porto Alegre: Fabris, 2006.

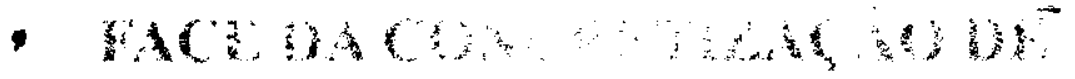

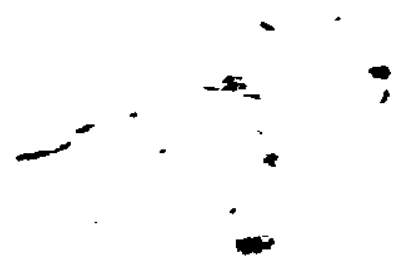

Revista Esmat, Palmas, Ano 2, $n^{\circ} 2$, pag. 7 a 27 - jan/dez 2010

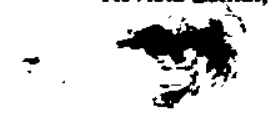

